\title{
Values Align for Researching Whole Systems: A Reflective Overview of the Special Issue
}

\author{
John Weeks, Heather Boon, ${ }^{2}$ and Cheryl Ritenbaugh ${ }^{3}$
}

\begin{abstract}
"In the broader context of the call of Berwick and others toward a multiyear march of the medical industry to become a true health care system, it is possible that the whole system research conversation of 20 years ago was the right conversation, ahead of its time. Perhaps that conversation's time of latency is over. What is certain is that we need to be putting new thinking and new research resources behind new kinds of questions if we are to effectively assess the outcomes of this new/old approach to health." (Gaudet)

- Tracy Gaudet, MD and Ben Kligler, MD, MPH

Office of Patient Centered Care and Cultural Transformation, Veterans Health Administration
\end{abstract}

\section{Context: Convergence of Values}

W E ENGAGED THIS SPECIAL ISSUE PROJECT to foster what we believe is a useful convergence. On one hand, members of our team (Table 1) have worked for many years to develop and apply research methods that suit the characteristics of traditional and integrative health practices. These typically have complex features: multimodal, individualized, patientcentered, lifestyle oriented, whole person, health-focused, and oriented toward effectiveness. Together, they seemed to have about as much opportunity to be appropriately measured through the historic gold standard of randomized controlled trials as a camel has of passing through the eye of a needle. We perceived that we needed new methods. We grouped these as "whole systems research" (WSR). ${ }^{1,2}$

In 2001, a North American group of scientists met to examine options. ${ }^{3}$ We did not foresee that solutions would come quickly. Two years later in 2003, we formed an international organization of researchers in traditional, complementary, alternative, and integrative medicine. The goal of the organization, ISCMR - a supporting partner for this special issue-is to "foster the development and dissemination of new knowledge regarding whole person healing and whole systems healthcare research." 4 The background section of the review led by Ijaz in this issue describes in more detail the biomedical research context and our past and present challenges. For instance, table 1 in that article describes the "Characteristics of Clinical Whole Systems Paradigms for 13 distinct fields." (Ijaz) From these origins, the WSR movement made contributions to the broader research community. Notable was that of MacPherson, ${ }^{5}$ Witt,

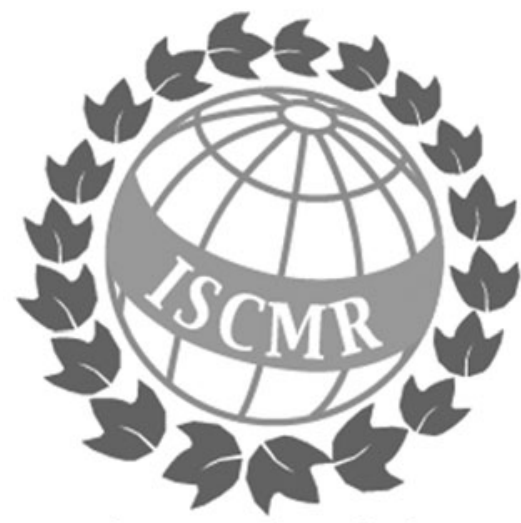

Researchers in Traditional, Alternative, Complementary and Integrative Medicine and Health

Berman, and others in furthering pragmatic trial designs. ${ }^{6}$ Yet a hoped-for movement for "whole systems research" that matched what we originally perceived as a need to move medicine toward whole systems solutions to health care delivery-for expensive chronic conditions, in particular, and for problem solving in general-has not, to date, emerged inside biomedical circles.

Yet concurrently in this time period, we are observing remarkable familiar-sounding changes in the dominant biomedical research and delivery paradigm that reflect what were our original priorities. Many of the values that we were seeking to explore have begun to be identified and highlighted in the

\footnotetext{
${ }^{1}$ Editor-in-Chief, The Journal of Alternative and Complementary Medicine.

${ }^{2}$ Leslie Dan Faculty of Pharmacy, University of Toronto, Toronto, Ontario, Canada.

${ }^{3}$ Department of Family and Community Medicine, University of Arizona, Tucson, AZ.
} 
Table 1. Special Issue Editorial Team

\begin{tabular}{ccc}
\hline Heather Boon, BScPhm, PhD & Barb Findlay Reece, RN & Stephanie Taylor, PhD \\
University of Toronto & Past VP, Samueli Institute & Vetans Administration \\
Patricia Herman, ND, PhD & Jennifer Rioux, PhD, AD, C-IAYT & Peter Wayne, PhD \\
RAND Corporation & Integral Ayurveda and Yoga Therapy & Harvard/Brigham and Women's \\
Jianping Liu, PhD & Cheryl Ritenbaugh, PhD, MPH & John Weeks \\
Beijing University of Chinese Medicine & University of Arizona & JACM; The Integrator Blog \\
President, ISCMR & Dugald Seely, ND & Claudia Witt, MD, MBA \\
Scott Mist, PhD, MAOM, MS, MA, LAc & Ontario Integrative Cancer Center & University of Zurich \\
Oregon Health \& Science University & Leanna Standish, PhD, ND, LAc & \\
& Bastyr University & \\
& &
\end{tabular}

mainstream of biomedicine. In the United States, turning in this direction may be traced to the 1999 National Academy of Medicine study "To Err is Human."7 That report split the bestin-the-world image that cloaked the corpus of U.S. medicine, revealing the 100,000 lives lost to usual care-now exceeding 250,000 by some estimates - making it the U.S.'s third most powerful cause of death. ${ }^{8}$ For many, this nightmarish awakening provoked calls for transformative change.

Efforts to undo the causes of these losses began promoting a shift from focusing on "volume" to a focus on "value." 10 The former administrator for the U.S. Center for Medicare and Medicaid Services, Donald Berwick, called for a shift from disease management to a "health creating" paradigm. ${ }^{11}$ A proposed shift in mission at a Harvard Medical School captures the realignment from "alleviating human suffering caused by disease" to "improve health and wellness for everyone." 12 The U.S. Veterans Administration (VA) began seeking to implement such a whole system change, establishing an Office of Patient-Centered Care and Health System Transformation-which is featured in an article and a commentary in this issue-and commencing a system-wide campaign toward a "whole health" model (Taylor, Gaudet).

The dominant school of medicine's tactics for fostering this newly focused value-based care included resonant considerations and directions: interprofessionalism, patient centeredness, cultural sensitivity, behavioral and social determinants of health, personalized care, stress reduction, and outcomes of well-being and resilience (Table 2). Backing these was the growing realization that suppression of disease is not creation of health. ${ }^{13,14}$ These aims birthed new methods for examination: patient-reported outcomes, pragmatic trials, and implementation research, to name a few. The invited commentary led by Elder in this issue explores

TABle 2. Convergence of Interests: Whole Systems Research and Value-Based Medicine

Whole system research

Challenging clinical

characteristics

Value-based medicine Key considerations

Team care

Patient centered

Individualized/tailored

Lifestyle (diet, exercise, stress, self-care)

Health and wellness

Multimodal (mind-body-spirit) Effectiveness

Interprofessionalism

Patient centered

Personalized

Behavioral determinants

Resilience and well-being

Chronic disease models Outcomes the convergence of these with the original WSR aims, through reference to the WSR exemplars in the Ijaz review.

In this convergent context, we issued our call for articles. ${ }^{15}$ We intentionally cast a wide net for what we chose to call the Special Issue on Multimodal Approaches in Integrative Health: Whole Persons, Whole Practices, Whole Systems. The submissions fell neatly into two distinct groups. One was a set of research articles from researchers at not-for-profit, state, and national entities focusing on methods to transform treatment toward multimodal teambased integrative whole system models. The focus of virtually all of these was on treatment of pain. The second is a group of new exemplars of multimodal and whole systems analyses to which we invited the Ijaz-led analysis of 41 historic WSR exemplars, Whole Systems Research in Health Care: A Scoping Review.

\section{Transforming Systems of Pain Treatment Toward Integrative Health}

The crisis in chronic pain treatment in the United States and beyond, due to almost sole reliance on pharmaceutical approaches that became visible in recent years as "the opioid crisis," runs concurrent with the submission of most of these articles. Governmental agencies, hospitals, and other medical delivery organizations alike are seeking to implement approaches to pain treatment that better integrate nonpharmacologic practices and practitioners. Multiple guidelines and policy documents urge this multimodal interprofessional direction. ${ }^{16-18}$ In some cases, as will be seen, organizations have engaged the issues with striking whole systems strategies.

The invited commentary from Gaudet and Kligler-quoted at the top of this article-describes the plans of the U.S. Veterans Health Administration to transform the agency to a "whole health" model. Pain, opioids, and post-traumatic stress disorders (PTSDs) of returning soldiers drive the efforts, led by these two integrative health and medicine veterans, to reframe the mission of this government-funded single-payer entity. In the invited commentary "Whole Health in the Whole System of the Veterans Administration: How Will We Know We Have Reached This Future State?" the two leaders describe their strategy. They share atypical research questions and measures to clarify whether the VA is reaching the desired "future state" of creating whole health. The VA's transformational road has its distinctive hurdles and illuminations. In "What Should Health Care Systems Consider When Implementing Complementary and Integrative Health: Lessons from Veterans Health Administration," Taylor et al. 
share nine key factors facilitating implementation of complementary and integrative health approaches in that nation's largest health care systems, together with seven areas where challenges are routinely arising.

Moving from that nationwide entity to the U.S. state of Oregon, lawmakers there faced their own crisis from overreliance on pharmaceuticals. They passed a law to push treatment of back and neck pain toward a multimodal system that includes nonpharmacologic treatments by acupuncturists, chiropractors, yoga practitioners, massage therapists, mindbody practitioners, and others. The target is an underserved population for whom health care is paid by the government, like that at the VA. In "Whole Systems Within Whole Systems: The Oregon Health Plan's Expansion of Services for Back and Neck Pain," Eaves et al. employ a "whole systems framework" to explore the implementation of the new guidelines. (Eaves) Theirs was a "multilevel framework designed to consider the multiple actors and level of influence that [Oregon Health Plan] administrators and our research team expected would influence implementation before beginning our evaluation.'" Using survey data and interviews, the article's implementation-orientation identified the high level of complexity encountered when changes are sought that impact so many aspects of the organization of health care.

An underserved population for whom services are typically also government funded is the subject of the article led by Hursak entitled "Design, Implementation, and Evaluation of an Integrative Pain Management Program in a Primary Care Safety-Net Clinic." Although part of the state of California's public health system, the context is in contrast with the Oregon article in that here the researchers explore the implementation of a multipractitioner integrative model in a single clinic. The method is a group-based service model through which clinicians and administrators lead those they serve to other services. It could inform development, for instance, of individual Oregon clinics seeking to elevate their nonpharmacologic offerings.

A common denominator across these three articles is that the initiative to change treatment is for populations with high trauma: veterans returning from war, and underserved and economically stretched individuals and families who use state-funded services. Is it possible that the multimodal whole person whole systems methods are particularly valuable-as compared with single-agent pharmaceutical methods-for populations that are complicated by trauma and poverty?

This theme of serving a population with high levels of historic trauma continues in Drost's work in a government-run clinic in a Canadian province in which team members sought to follow the guidelines of that nation's Truth and Reconciliation Commission by incorporating indigenous healing practices in provincial health care. In "Developing the Alliances to Expand Traditional Indigenous Healing Practices Within Alberta Health Services," the focus is on the inclusion of the traditional use of sweat lodges into a single health care center. Yet the author engaged the project to illuminate strategies for others seeking these and other culturally appropriate ways to serve indigenous people throughout the jurisdiction.

A key factor for success among the nine in the VA study was "demonstrating evidence of [complementary and integrative health] effectiveness." (Taylor) In "Employing Evidence in Evaluating Complementary Therapies: Finding from an Ethnography of Integrative Pain Management at a Large Urban Pediatric Hospital,' Roth and others engaged a series of interviews with representatives of multiple stakeholders to better understand how evidence has meaning in the effort to create changes toward complementary and integrative approaches. Their five themes demonstrate how this seemingly static concept takes multiple forms in shaping the interest and action of key parties. Access to quality electronic health data to inform the shift toward multidisciplinary integrative pain treatment is the subject of a brief commentary from Ye and others entitled "Improving Usability of Electronic Health Records for Whole Systems Integrative Medicine Practitioners.",

In private not-for-profit health care institutions, sustainability is frequently an issue. In "Implementing an Integrative Survivorship Program at a Comprehensive Cancer Center: A Multimodal Approach to Life After Cancer,' Glaser et al. take a narrative approach to describe how this program was developed and grew to eventually include integrative modalities such as healing touch, yoga, oncology massage, and, through partnerships with community practitioners, acupuncture. A team led by Hansen at an academic medical center in the central United States shares their success for a nurse and health coaching-oriented strategy in "A Replicable and Sustainable Whole Person Care Model for Chronic Pain." The model similarly grew organically based on available resources - in this case nurses trained in health coaching who are at the program's center. These distinctive characteristics suggest that the replicability and sustainability may not be precisely in the provider mix but rather in the process choices of making the most of the human resources and relationships in a given site, and the practice of solidifying the model in a step-by-step way. This set of articles taken together provides guidance as to both the consistencies and variations to be found among challenges and solutions in this arena.

\section{Exemplars of Multimodal and Whole Person Treatments}

This body of pain-related efforts to transform whole systems of treatment at multiple clinic, hospital, state, and national levels already described arrived as a surprise. What we knew we wished to draw were the latest clinical exemplars examined through WSR and multimodal research methods. A part of the mission to anchor this work was to reflect on the opus of WSR over the past two decades and examine it systematically, particularly with reference to whether any of the methods in these exemplars might have utility for research colleagues in biomedicine who find themselves confronted with the complexities of measuring interventions that meet the interprofessional, patient-centered, and other outcomes of the emerging value-based era.

In "Whole Systems Research in Health Care: A Scoping Review," Ijaz and a team, supported by many of the members of the Special Issue Editorial Team, identified a set of 41 historical clinical research exemplars. These reflect treatment in 13 traditional, complementary, and integrative medicine disciplines. The aim was to map "the range and methodological characteristics of WSR studies." (Ijaz)

The invited project, supported, in part, through funds for the special issue, includes multiple charts that can guide newcomers as well as WSR veterans through the choices 
and exemplars. The goal was to explore methods rather than effectiveness. One chart explores the design, interventions, and outcomes of each study. Another examines the research strategies in each. Eighteen use randomized methodsalthough only a few were controlled-and another 14 depend on statistical (4) or pragmatic (10) allocation designs. Although the gold standard of a single-agent randomized placebo-controlled trial could not by definition be met in these studies, it is notable that these WSR scientists were typically able to apply research methods developed in the biomedical framework-including more recent methods in the value-based era such as pragmatic trials.

The development of a complex whole system intervention by Seely and a Canadian team documented in "Intervention Development Process for a Pragmatic Randomized Controlled Trial: The Thoracic Peri-Operative Integrative Surgical Care Evaluation Trial" is already an exemplar in how to herd the famously individually minded cats of integrative practice-in this case naturopathic doctors-to define the "intervention palette with core and optional components." Although the work began with multiple systematic reviews, the demonstrated genius may be in the 32 member "Intervention Development Committee" on which 14 medical doctors from 5 specialties and multiple research scientists worked shoulderto-shoulder with the naturopathic clinicians and researchers to set the intentionally malleable clinical guidelines. Selection assignment was based on a systematic analysis of five factors ranging from "practical usage" and "safety" to "holism across goals," "feasibility and scalability," and "evidence for effectiveness." In this case, the process appears also to be part of the outcome. Naturopathic doctors are seeking to create relationships with medical colleagues and would appear to have done so in the process of the research itself.

Rioux and Howerter took a different tack in their plunge into a WSR method that they reported as "Outcomes from a Whole-Systems Ayurvedic Medicine and Yoga Therapy Treatment for Obesity Pilot Study." Here the model is one of the first in the WSR field to honor both the biomedical and Ayurvedic models throughout design and implementation. Study design involved dual diagnosis (biomedical and Ayurvedic) at baseline as well as individualized treatments including diets based in Ayurvedic food classifications (creamy, astringent, etc.) and Yoga tailored to dosha imbalance, body habitus, and abilities. Perhaps the most novel component of the design was measurement of both biomedical and Ayurvedic outcomes.

The other two exemplars each reports outcomes of multimodal interventions directly or indirectly pain related. In "Evaluation of an Integrative PTSD Treatment Program," Hilton et al. used a mixed-methods approach to evaluate "Back on Track," an intensive outpatient "whole systems approach for the treatment of combat-related stress reactions and PTSD in active duty service members." Quantitative data were evaluated on 585 soldiers who underwent the "psychoeducational group therapy format with a holistic approach for treating combat stress, increasing resiliency, and assisting with reintegration" through content "in biopsycho-social-spiritual domains, including didactic lectures on mindfulness and the relaxation response and daily sessions of yoga nidra and meditation." (Hilton) The authors discuss how the value found surpasses the results of either "gold standard cognitive behavioral therapy" or individual
Side-Bar 1. Comparing Apples with Catastrophes: Whole Costs Needed to Assess Whole System Methods

The marquee results in the integrative team cost analysis by Wayne et al. will not please the integrative health advocate who assumes that integrative services are cost effective. In that Boston, Massachusetts-based medical delivery center fueled by a mix of private and government insurance methods, the total adjusted annual chronic low back pain-related costs per patient were nearly $70 \%$ greater than similarly insured people with usual care. Yet at the same time, the authors noted "trends towards decreased direct expenditures and medication usage over time." They urged further research with, among other changes, "longer observational periods [that] explore multiple metrics of cost-effectiveness." Their multimodal team-based approach potentially met neither the time nor cost dimensions of an optimal "whole system" framework.

Consider the same team intervention inside the Veterans Administration's "whole health" campaign as described by Gaudet and Kligler. The VA's lifetime relationship with the veteran and his or her family creates interest in a longer "observation period" than, for example, the annual insurance policy bazaar that defines an insurer's commitment to a patient in the U.S. private insurance system. The VA's singlepayer environment also incentivizes interest in considering all the costs that might be associated with the veteran's care. These include such expensive human and financial challenges as addiction, family disruption, in-patient treatment, and homelessness. These are associated with pharmacologic measures for pain management. They are not associated with the nominally more expensive care from an integrative team of acupuncturists, chiropractors, integrative medical doctors, and others found by Wayne and his team. Considered in this context, their limited framework suggests they were comparing apples to catastrophes.

The multiple submissions to this Special Issue on Multimodal Approaches in Integrative Health that focus on the care for populations with high levels of trauma-returning soldiers, indigenous people, and those who are economically disadvantaged - underscore a related insight. Reductive narrow lens approaches to pain and treatment in general may more readily fit the needs of advantaged people. But when the complexities attached to trauma are part of the picture, human-connected treatment that engages the whole person-which may be comparatively cost-intensive in the limited frame of the interventioncould prove to be both the most effective and cost-effective, under full cost accounting (Side-Bar 2). Increasing funding of research directed at applying better methods for measuring such complex outcomes will be needed.-J.W., H.B., and C.R.

complementary medicine treatments. (Hilton) The holistic combination seems to be linked to the effect.

While also multimodal, the context, content, and delivery are significantly different in the contribution from Wayne et al. entitled "Cost-effectiveness of a team-based integrative medicine approach to the treatment of back pain." The multidisciplinary treatment at a large tertiary care hospital and its associated clinics included treatment from an 
interprofessionally trained team that delivered "chiropractic, acupuncture, psychiatry, physician-administered integrative medicine consultations, and multiple mind-body and movement-based therapies." (Wayne) The findings were mixed with questions regarding changes over a longer term that beg questions (Side-Bar 1) about the extent to which the payment model, delivery context, and the application of whole system accounting will ultimately be the determining factors regarding the clinical and cost value to be gained from these whole person multimodal interventions.

\section{Reflections on the Project}

The value in exploring this convergence of the integrative clinical concerns that WSR seeks to address and the directions in the value-based era are suggested by two invited commentaries. As multimodal approaches have risen in value for major chronic disease, a subset of physicians have formed an international organization focused on "lifestyle medicine." In "The Need for a Whole Systems Approach to Evidence Evaluation: An Update from the American College of Lifestyle Medicine," Katz and Karlsen announce the challenging work underway from this group to clarify appropriate methods "in which the entire model of care is deemed the 'active ingredient' [and thus] require assessment of the entire model of care versus other models." (Katz) Their proposed Hierarchies of Evidence Applied to Lifestyle Medicine (HEALM) project, in development, promises to be an interesting addition to the WSR methodology oeuvre.

That is a coming attraction. For the present moment, an invited commentary from Elder et al. sought to share highlights from the body of WSR methods and exemplars that might be the most useful to researchers who are also grappling with how to measure the more complex and individualized interventions of the value-based era. In "Convergent Points for Conventional Medicine and Whole Systems Research: A User's Guide," the team extracts from the Ijaz review of 41 WSR trials those examples that might prove of most utility across "four potentially cross-talking themes-complex behaviorally-focused interventions, patient centered outcomes, team-based care, and resilience and well-being." (Elder)

The response to the call for articles was striking in both categories of responses. Despite significant efforts to reach communities of researchers who are applying WSR methods, the yield was quite limited, despite the fact that special issues that declare for WSR are rare. Assuming the light response was not a marketing failure, one wonders, ironically, if at just this convergent moment when whole systems thinking is on the rise, if the energy in the movement for WSR is on the decline. In private conversations and published statements, adherents share challenges in securing funding. ${ }^{19}$ An organized effort to convince the largest funding entity for complementary and integrative health to prioritize "researching the way we practice" in multimodal integrative clinical has produced limited response. ${ }^{20} \mathrm{Can}$ it be that former WSR researchers have become pragmatic trialists-a direction that their ranks arguably fostered? Or are they seeking to approximate capturing the whole through mixed methods research? How comfortable can researchers, payers, and policymakers, for that matter, be with trials that may knit together patient-reported outcomes, biomedical,

\section{Side-Bar 2: Advance the Dialogue: An Invitation for Commentaries on the Special Issue}

We hope that the perspectives and findings in this editorial and commentaries, the Ijaz scoping review, and the original research articles in this Special Issue on Multimodal Approaches in Integrative Health: Whole Persons, Whole Practices, Whole Systems prove stimulating. To expand and advance the dialogue on the multiple themeswhether related to a method or conclusion in a single article, the state of the whole systems research movement, measures needed to reach the "future state" of whole health, or strategies to support implementation research in these areas-we invite your commentary of up to 500 words on a topic of your choice that ties back to content here. Please submit them to JACM by April 30, 2019, with a cover note identifying them as responsive to this call. We will work with the Special Issue Editorial Team to select articles for publication.-C.R., H.B., and J.W.

and cost data as Seely does in the trial included in the Ijaz review? ${ }^{21}$

At the same time, we were struck by the series of articles that focus on something that could not be anticipated in the more polarized era 20 years ago: namely, the transformation of whole systems of care toward including nonpharmacologic practices and practitioners in an integrative health model. These new models for delivery of health urge a new application of research methods that fit a new paradigm of care (Side-Bar 2). Gaudet and Kligler ask through what measures and methods the Veterans Health Administration can know that the largest health care system in the United States has reached the "future state" of "whole health." The transformation of care in multiple centers, hospitals, and under new national, state, and provincial regulations-examined in the other articles-is microcosms of reframing of what researchers need to be asking.

The farmer, poet, and author Wendell Berry has written of the importance of maintaining wilderness at the borders of farmlands for the sake of biological diversity for the health of the land and, by extension, the planet. ${ }^{22}$ The emerging appreciation of whole systems thinking in health care, whether related to the microbiome or to the social determinants of health, suggests that tilling the soil of WSR methods, by whatever names, merits not dismissal, but investment.

\section{Acknowledgments}

This special issue was supported by a grant from the Lotte \& John Hecht Memorial Foundation. It was engaged with the fiscal partnership of Bastyr University, Bothell, WA, offering programs in areas including naturopathy, acupuncture, and Oriental medicine, nutrition, herbal medicine, Ayurvedic medicine, psychology, and midwifery. We also thank ISCMR, a global organization that networks researchers in traditional, complementary, alternative, and integrative health and medicine for their partnership in promoting this issue.

\section{References}

1. Ritenbaugh C, Verhoef M, Fleishman S, et al. Whole systems research: A discipline for studying complementary 
and alternative medicine. Altern Ther Health Med 2003;9: 32-36.

2. Verhoef M, Lewith G, Ritenbaugh C, et al. Complementary and alternative medicine whole systems research: Beyond identification of inadequacies of the RCT. Complementary Ther Med 2005;13:206-212.

3. Tzu Chi Institute for Complementary Medicine. Tzu Chi Institute for Complementary Medicine Conference: Art and Science of Healing II. Vancouver, BC, October 19-21, 2001.

4. About ISCMR. Webpage, ISCMR-Researchers in Traditional, Complementary, Alternative and Integrative Medicine and Health. Online document at: https://www.iscmr.org/ content/about-iscmr, accessed February 17, 2019.

5. Macpherson H. Pragmatic clinical trials. Complement Ther Med 2004;12:136-140.

6. Witt CM, Withers SR, Grant S, et al. What can comparative effectiveness research contribute to integrative health in international perspective? J Altern Complement Med 2014; 20:874-880.

7. Kohn LT, Corrigan JM, Donaldson MS, eds. To Err is Human: Building a Safer Health System. Institute of Medicine (US) Committee on Quality of Health Care in America. Washington, DC: National Academies Press (US), 2000.

8. Makary MA, Daniel M. Medical error-the 3rd leading cause of death in the US. BMJ 2016;353:i2139.

9. Berwick DM, Calkins DR, McCannon CJ, Hackbarth AD. The 100,000 lives campaign: Setting a goal and a deadline for improving health care quality. JAMA 2006;295:324327.

10. NEJM Catalyst. What is Value-Based Health Care. New Marketplace. N Engl J Med. Online document at: https:// catalyst.nejm.org/what-is-value-based-healthcare, accessed February 17, 2019.

11. Weeks J. Hooking up: Don Berwick, integrative medicine and his call for a radical shift to 'health creation.' Huffington Post. 2014. Online document at: www.huffingtonpost.com/ john-weeks/don-berwick-integrative-m_b_4781105.html, accessed February 17, 2019.

12. Weeks J. Paradigm Shift? Harvard Medical School Considering Mission Reframe from Sickness Model to Health. Today's Practitioner. 2018. Online document at: https:// todayspractitioner.com/john-weeks/paradigm-shift-harvardmedical-school-considering-mission-reframe-from-sicknessmodel-to-health/\#.XGsQKrh7mM8, accessed February 17, 2019.

13. Weinstock M. Toward a healthier tomorrow. Hospital and Health Networks Web site. 2013. www.hhnmag.com/ display/HHN-news-article.dhtml?dcrPath=/templatedata/ HF_Common/NewsArticle/data/HHN/Magazine/2013/Dec/ 1213HHN_Coverstory, accessed April 14, 2014.

14. Stempniak M. The patient experience: Taking it to the next level. Hospital and Health Networks Web site. 2013. On- line document at: www.hhnmag.com/display/HHN-newsarticle.dhtml?dcrPath=/templatedata/HF_Common/NewsArticle/ data/HHN/Magazine/2013/Apr/0413HHN_FEA_Patient experienceGate, accessed April 14, 2014.

15. Weeks J. Multimodal approaches in integrative health: Whole persons, whole practices, whole systems-an invitation to submit. J Altern Complement Med 2018;24:193195.

16. Joint Commission. Clarification on the Pain Management Standard. Clarification to Standard PC.01.02.07. Online document at: https://www.jointcommission.org/assets/1/18/ Clarification_of_the_Pain_Management_Standard.pdf, accessed February 17, 2019.

17. Oaseem A, Wilt TJ, McLean RM, et al. Clinical Guidelines Committee of the American College of Physicians. Noninvasive Treatments for Acute, Subacute, and Chronic Low Back Pain: A Clinical Practice Guideline. American College of Physicians. Annals of Internal Medicine. Clinical Guidelines. 2017. Online document at: https://annals.org/ aim/fullarticle/2603228/noninvasive-treatments-acutesubacute-chronic-low-back-pain-clinical-practice, accessed February 27, 2019.

18. Phillips JK, Ford MA, Bonnie RJ, eds; National Academies of Sciences, Engineering, and Medicine; Health and Medicine Division; Board on Health Sciences Policy; Committee on Pain Management and Regulatory Strategies to Address Prescription Opioid Abuse. Pain Management and the Opioid Epidemic: Balancing Societal and Individual Benefits and Risks of Prescription Opioid Use. Washington (DC): National Academies Press (US), 2017.

19. Ritenbaugh R, Aickin A, Bradley R, et al. Whole systems research becomes real: New results and next steps. J Altern Complement Med 2010;16:131-137.

20. Menard M, Weeks J, Anderson B, et al. Consensus recommendations to NCCIH from research faculty in a transdisciplinary academic consortium for complementary and integrative health and medicine. J Altern Complement Med 2015;21:386-394.

21. Herman PM, Szczurko O, Cooley K, et al. A naturopathic approach to the prevention of cardiovascular disease: Costeffectiveness analysis of a pragmatic multi-worksite randomized clinical trial. J Occup Environ Med 2014;56:171-176.

22. Berry W. An argument for diversity. Hudson Rev 42:537548.

Address correspondence to: John Weeks johnweeks-integrator.com Seattle, WA 98116

E-mail: jweeks.jacm@gmail.com 